\title{
An HIV-infected patient with coronavirus disease 2019 has a favourable prognosis: a case report
}

\author{
Chong Tian ${ }^{1 \# \wedge}$, Lei Tang ${ }^{1 \#}$, Jiahong Wu ${ }^{2}$, Wuchao Li ${ }^{1}$, Xing Ming ${ }^{1}$, Hourong Zhou ${ }^{3}$, Weidong Wu ${ }^{4,5}$ \\ Xianchun Zeng ${ }^{1,5}$ \\ ${ }^{1}$ Department of Medical Imaging, Guizhou Provincial People's Hospital, Guiyang, China; ${ }^{2}$ School of Basic Medicine, Guizhou Medical University, \\ Guiyang, China; ${ }^{3}$ Department of Emergency, Guizhou Provincial People's Hospital, Guiyang, China; ${ }^{4}$ Guizhou Normal College, Guiyang, China; \\ ${ }^{5}$ Jiangjunshan Hospital, Guiyang, China \\ \#These authors contributed equally to this work. \\ Correspondence to: Xianchun Zeng. Department of Medical Imaging, Guizhou Provincial People's Hospital, Zhongshan East Road 83, Guiyang \\ 550002, China. Email: zengxianchun04@foxmail.com.
}

\begin{abstract}
The coronavirus disease 2019 (COVID-19), caused by severe acute respiratory syndrome coronavirus 2 (SARS-CoV-2), has spread rapidly, which now has turned into a pandemic. The new emerging infectious disease has raised many challenges and uncertainties regarding disease management and prognosis in immunocompromised patient populations. The risk of COVID-19 among people living with human immunodeficiency virus (HIV) has different opinions. Some scholars speculated that patients with HIV may be at decreased risk for complications of COVID-19 because HIV antiretroviral medications may have activity against coronaviruses such as SARS-CoV-2. But others have the opposite because of the immunosuppression for HIV patients. Here we reported a case of HIV-infected patient confirmed with COVID-19 and had a favourable prognosis. The patient was a 24-year-old male who was diagnosed with HIV infection 2 years ago and then followed a regular antiretroviral therapy (ART). After infected with COVID-19, the patient had no other clinical symptoms and laboratory abnormalities throughout the course of the disease except presented with fever for a short-term (2 days), and no secondary infection or exacerbation occurred after admission in hospital. Follow-up chest CT showed that the lung lesions disappeared within a short period of time. After standard treatment by 9 days, the patient was cured and discharged. This report highlights the importance of ART for HIV-infected persons, and with regular ART for HIV patients may reduce adverse consequences after infection with COVID-19.
\end{abstract}

Keywords: Coronavirus disease 2019 (COVID-19); severe acute respiratory syndrome coronavirus 2 (SARSCoV-2); human immunodeficiency virus (HIV); case report

Submitted Mar 06, 2020. Accepted for publication Jul 17, 2020.

doi: 10.21037/apm-20-576

View this article at: http://dx.doi.org/10.21037/apm-20-576

\section{Introduction}

By July 14, 2020, the pandemic of novel coronavirus disease 2019 (COVID-19) caused by severe acute respiratory syndrome coronavirus 2 (SARS-CoV-2) has accumulated over 12.96 million confirmed cases and more than 570,288 deaths (1). Epidemiological analysis of COVID-19 found that the severe and extremely severe illnesses and deaths of COVID-19 mainly occurred in adult males with impaired immune functions and underlying medical conditions, and some had bacterial and fungal infections (2,3). Little is known, however, about the COVID-19 in a patient with human immunodeficiency

\footnotetext{
^ ORCID: 0000-0001-8309-4951.
} 


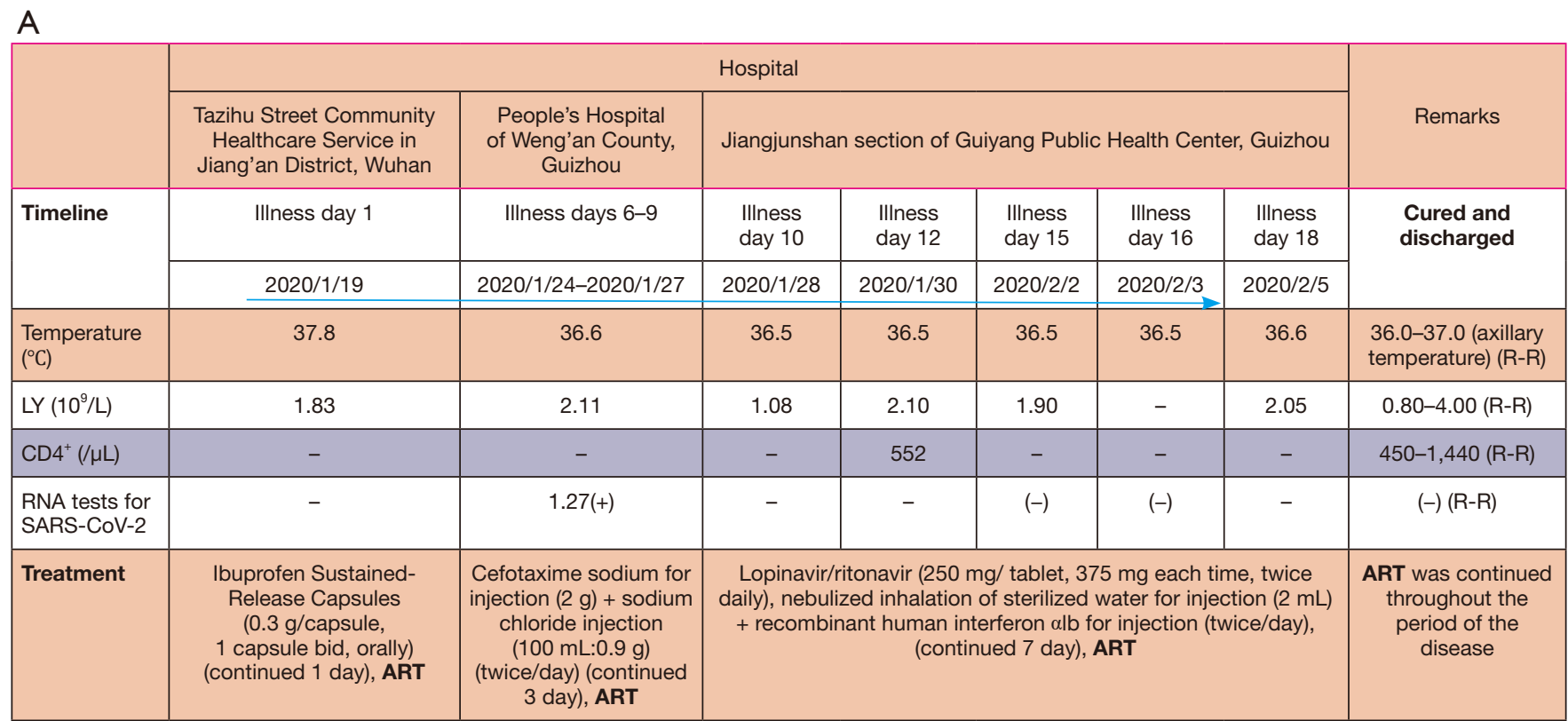
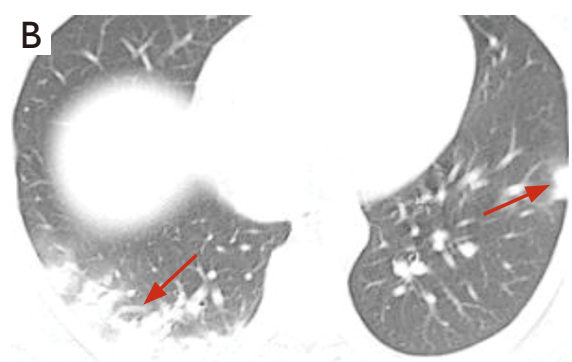

January 24,2020

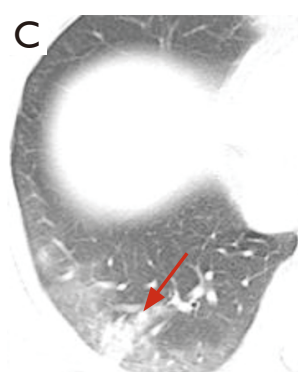

January 26,2020
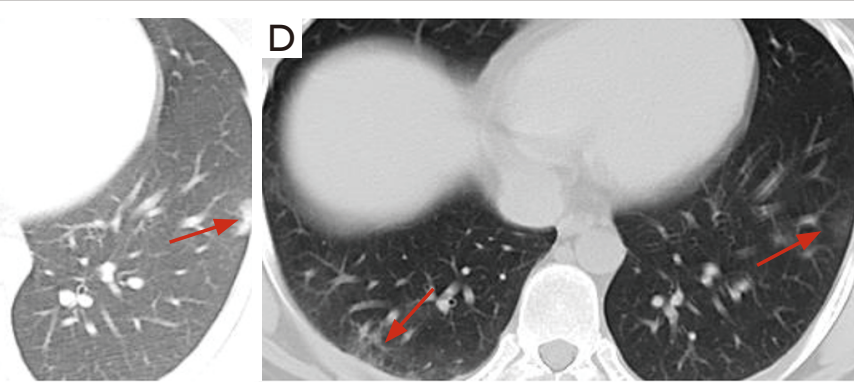

February 03, 2020

Figure 1 Time line for each treatment and follow-up chest CT. The blue arrow represents the continuity of time, indicating that the course of the disease is a continuous process. (A) Time line and duration of treatment, mainly including time line to hospital, clinical symptoms (no symptoms except fever), lymphocyte count (LY), CD4 ${ }^{+} \mathrm{T}$ lymphocytes, RNA tests for SARS-CoV-2 and treatment process; ART: comprising tenofovir (0.3 g, orally, q.d.), lamivudine ( $0.3 \mathrm{~g}$, orally, q.d.), and efavirenz ( $0.6 \mathrm{~g}$, orally, q.d.). Follow-up chest CT showed that the lung lesions (red arrows) disappeared within a short period of time (B,C) and a few fibrotic lesions in the lungs finally (D). SARS-CoV-2, severe acute respiratory syndrome coronavirus 2; R-R, reference range; ART, antiretroviral therapy.

virus (HIV) infection. HIV is a retrovirus that attacks the human immune system by destroying $\mathrm{CD}^{+} \mathrm{T}$ cells (4). Therefore, theoretically, HIV-infected patients with COVID-19 may have more severe clinical presentations and be harder to cure. Though there is no significant evidence to support people with co-infection of SARSCoV-2 and HIV is worse clinical performance and prognosis, previous case reports indicate favorable prognosis for these co-infected patients that were already receiving ART (5-7). In this report, we retrospectively described a 24-year-old male patient of well-controlled HIV by ART showed non-serious manifestation when co- infecting with SARS-CoV-2. We present the following article in accordance with the CARE reporting checklist (available at http://dx.doi.org/10.21037/apm-20-576).

\section{Case presentation (Figure 1)}

The case was a 24-year-old male, who was diagnosed with HIV infection 2 years ago and then followed a regular ART comprising tenofovir ( $0.3 \mathrm{~g}$, orally, q.d.), lamivudine ( $0.3 \mathrm{~g}$, orally, q.d.), and efavirenz (0.6 g, orally, q.d.). He has been working in Wuhan of Hubei Province, and reported no exposure to Huanan seafood market, no contact with 
patients infected with COVID-19, no history of eating wild animals, and no history of raising pets at home. On January 19, 2020, he initially reported fever for unknown reasons (temperature up to $37.8^{\circ} \mathrm{C}$ ), and visited the Tazihu Street Community Healthcare Service in Jiang'an District of Wuhan. Blood routine tests, C-reactive protein (CRP) test, and examinations for influenza $\mathrm{A}$ and $\mathrm{B}$ viruses all had normal findings. He was prescribed Ibuprofen SustainedRelease Capsules ( $0.3 \mathrm{~g} /$ capsule, 1 capsule bid, orally, continued 1 day), and the body temperature returned to normal on the next day.

On January 22, 2020, he went back to his hometown in Weng'an County, Guizhou Province. He received a first chest computed tomographic (CT) scan in a hospital in Weng'an County as to the request of the local Center for Disease Control (CDC) on January 24, 2020, because he was from Wuhan and had dry cough occasionally. The CT imaging showed bilateral multiple lower lobular infection loci (Figure 1B), making him highly susceptive of COVID-19. He was isolated immediately and received cephalosporin antibiotics [cefotaxime sodium for injection $(2 \mathrm{~g})+$ sodium chloride injection $(100 \mathrm{~mL}: 0.9 \mathrm{~g})$ (twice/ day)] to prevent infection, and meanwhile a nasopharyngeal swab was obtained and sent to the Guizhou Provincial CDC for RNA detection of SARS-CoV-2. On January 26, a second chest CT scan was performed, which showed significant improvement of pulmonary lesions (Figure 1C). On January 27, the RNA test reported the result of positive infection with SARS-CoV-2.

On January 28, the case was transferred to the designated Jiangjunshan Hospital in Guiyang, Guizhou Province. His temperature was $36.5^{\circ} \mathrm{C}$ at admission, with $\mathrm{SPO}_{2}$ of $98 \%$ (without oxygen inhalation) and occasional cough (not severe), but no sputum cough, chest tightness, or shortness of breath. According to the "Diagnosis and Treatment Plan for New Coronavirus Infected Pneumonia (Trial Fifth Edition)", he was given lopinavir/ritonavir $(250 \mathrm{mg} / \mathrm{tablet}, 375 \mathrm{mg}$ each time, twice daily), nebulized inhalation of sterilized water for injection $(2 \mathrm{~mL})+$ recombinant human interferon alb for injection (twice/day). Meanwhile, oral anti-HIV treatment with "tenofovir, lamivudine, and efavirenz" was continued. Antibiotics were discontinued.

During days 2-6 of hospitalization (days 11-15 of the disease course), the patient had stable signs, did not have cough symptoms, nor was fever, chest tightness, or shortness of breath presented. The treatment was continued as above. Hepatic and renal function, electrolytes, erythrocyte sedimentation rate (ESR), and CRP were tested twice, and both showed no abnormalities. Arterial blood gas analysis was performed for three times, and no abnormalities were shown. Blood test for $\mathrm{CD}^{+} \mathrm{T}$ lymphocytes was performed and showed no abnormalities (Figure 1A). Sampling was performed again on February 2 and 3, to re-test RNA of COVID-19.

During days 7-9 of hospitalization (days 16-18 of the disease course), the patient had stable signs. On day 7 of hospitalization (February 3, day 16 of the disease course), a third chest CT scan was performed, images showed a few fibrotic lesions in the lungs (Figure 1D). On day 9 of hospitalization (February 5, 2020, the 18th day of the disease course), both RNA tests for SARS-CoV-2 showed negative results. The liver and kidney function, electrolytes, ESR, CRP, and arterial blood gas analyses all showed normal results. Thus, the patient was discharged.

All procedures performed in studies involving human participants were in accordance with the ethical standards of the institutional and national research committees, and with the Helsinki Declaration (as revised in 2013). Written informed consent was obtained from the patient for publication of this case report and any accompanying images.

\section{Discussion}

Our case confirms that patients with HIV who have already under treatment with regular ART have no severe clinical presentation and poor prognosis of SARS-CoV-2 infection. The patient reported here had been under a regular ART when infected HIV 2 years ago. After onset of SARS$\mathrm{CoV}-2$ infection, he only presented a short-term fever and mild cough, and no secondary infection or exacerbation occurred after admission in hospital. The nucleic acid test revealed negative infection after a combination of lopinavir and ritonavir antiviral treatment, and chest CT scan showed absorption of pulmonary inflammatory exudation and minor presence of fibrotic lesions. Some scholars speculate that patients with HIV may be at decreased risk for complications of COVID-19 because their defective cellular immunity may reduce the possibility of the cytokine dysregulation that is associated with severe cases of COVID-19 (8-10). Previous literature simultaneously provides some evidence that HIV infection is associated with a milder course of severe acute respiratory syndrome (SARS) caused by SARS-CoV-1 and that HIV antiretroviral medications may reduce mortality and adverse prognosis from SARS (11).

Some studies also have shown that the community- 
acquired pneumonia caused a mortality of $6 \%$ to $15 \%$ in HIV-infected people, which was, however, largely decreased in HIV-infected patients under strict ART control, comparable to that among HIV-negative individuals (12). In addition, a regular ART can reduce the incidence of opportunistic infections and significantly reduce HIVrelated death, including death from respiratory infections $(13,14)$. Combined with the positive treatment outcome of this COVID-19 patient under a regular ART for HIV, we speculate that the anti-HIV drugs have an inhibitory or weakening effect on SARS-CoV-2 virus at the early stage of infection, thereby delaying or inhibiting the disease progress. On the other hand, this patient was young (24 years old), maintained a normal level of CD4 ${ }^{+}$ $T$ lymphocytes, and the absolute numbers of lymphocytes did not decrease during the disease course, indicating that the patient was at the early stage of asymptomatic HIV infection, having a relatively normal or a compensatory level of immune function as compared to the severely ill patients with COVID-19 or the advanced-stage AIDS patients, which may contribute to the milder symptoms of this patient $(4,15)$. Interestingly, no toxic side effects were observed during the lopinavir/ritonavir antiviral treatment, which may be due to the tolerance to lopinavir/ritonavir after long-term ART.

In conclusion, regular ART is of great importance for HIV-infected persons who unfortunately infected with COVID-19, which may help reduce clinical symptoms and improve prognosis.

\section{Acknowledgments}

Funding: This study was supported by the Guizhou Science and Technology Project \{QKHZC[2020]4Y002\}, the Guiyang Science and Technology Project \{ZKXM[2020]4\}, and the Guizhou Science and Technology Department Key Lab Project $\{\mathrm{QKF}[2017] 25\}$.

\section{Footnote}

Reporting Checklist: The authors have completed the CARE reporting checklist. Available at http://dx.doi.org/10.21037/ apm-20-576

Peer Review File: Available at http://dx.doi.org/10.21037/ apm-20-576

Conflicts of Interest: All authors have completed the ICMJE uniform disclosure form (available at http://dx.doi. org/10.21037/apm-20-576). The authors have no conflicts of interest to declare.

Ethical Statement: The authors are accountable for all aspects of the work in ensuring that questions related to the accuracy or integrity of any part of the work are appropriately investigated and resolved. All procedures performed in studies involving human participants were in accordance with the ethical standards of the institutional and national research committees, and with the Helsinki Declaration (as revised in 2013). Written informed consent was obtained from the patient for publication of this case report and any accompanying images.

Open Access Statement: This is an Open Access article distributed in accordance with the Creative Commons Attribution-NonCommercial-NoDerivs 4.0 International License (CC BY-NC-ND 4.0), which permits the noncommercial replication and distribution of the article with the strict proviso that no changes or edits are made and the original work is properly cited (including links to both the formal publication through the relevant DOI and the license). See: https://creativecommons.org/licenses/by-nc$\mathrm{nd} / 4.0 /$.

\section{References}

1. WHO. Coronavirus disease (COVID-19): Situation Report-176. https://www.who.int/docs/default-source/ coronaviruse/situation-reports/20200714-covid-19sitrep-176.pdf?sfvrsn=d01ce263_2 (accessed July 15, 2020).

2. Wang D, Hu B, Hu C, et al. Clinical Characteristics of 138 Hospitalized Patients With 2019 Novel CoronavirusInfected Pneumonia in Wuhan, China. JAMA 2020;323:1061-9.

3. Chen N, Zhou M, Dong X, et al. Epidemiological and clinical characteristics of 99 cases of 2019 novel coronavirus pneumonia in Wuhan, China: a descriptive study. Lancet 2020;395:507-13.

4. Fenwick C, Joo V, Jacquier P, et al. T-cell exhaustion in HIV infection. Immunol Rev 2019;292:149-63.

5. Haddad S, Tayyar R, Risch L, et al. Encephalopathy and seizure activity in a COVID-19 well controlled HIV patient. IDCases 2020;21:e00814.

6. Blanco JL, Ambrosioni J, Garcia F, et al. COVID-19 in patients with HIV: clinical case series. Lancet HIV 2020;7:e314-6. 
7. Vizcarra P, Pérez-Elías MJ, Quereda C, et al. Description of COVID-19 in HIV-infected individuals: a single-centre, prospective cohort. Lancet HIV 2020;7:e554-e564.

8. Joob B, Wiwanitkit V. SARS-CoV-2 and HIV. J Med Virol 2020;92:1415.

9. Mascolo S, Romanelli A, Carleo MA, et al. Could HIV infection alter the clinical course of SARS$\mathrm{CoV}-2$ infection? When less is better. J Med Virol 2020;92:1777-8.

10. Ridgway JP, Farley B, Benoit JL, et al. A Case Series of Five People Living with HIV Hospitalized with COVID-19 in Chicago, Illinois. AIDS Patient Care STDS 2020;34:331-5.

11. Chu CM, Cheng VC, Hung IF, et al. Role of lopinavir/ ritonavir in the treatment of SARS: initial virological and clinical findings. Thorax 2004;59:252-6.

12. Cilloniz C, Garcia-Vidal C, Moreno A, et al. Communityacquired bacterial pneumonia in adult HIV-infected patients. Expert Rev Anti Infect Ther 2018;16:579-88.

13. Barakat LA, Juthani-Mehta M, Allore H, et al. Comparing clinical outcomes in HIV-infected and uninfected older men hospitalized with community-acquired pneumonia. HIV Med 2015;16:421-30.

14. Malinis M, Myers J, Bordon J, et al. Clinical outcomes of HIV-infected patients hospitalized with bacterial community-acquired pneumonia. Int J Infect Dis 2010;14:e22-7.

15. Liu WJ, Zhao M, Liu K, et al. T-cell immunity of SARS$\mathrm{CoV}$ : Implications for vaccine development against MERS-CoV. Antiviral Res 2017;137:82-92.
Cite this article as: Tian C, Tang L, Wu J, Li W, Ming X, Zhou H, Wu W, Zeng X. An HIV-infected patient with coronavirus disease 2019 has a favourable prognosis: a case report. Ann Palliat Med 2021;10(5):5808-5812. doi: 10.21037/apm$20-576$ 